\title{
Impact of Age, Multimorbidity and Frailty on the Prescription of Preventive Antiplatelet Therapy in Older Population
}

\author{
Caroline Laborde ${ }^{1}$, Jérémy Barben ${ }^{1}$, Anca-Maria Mihai ${ }^{1}$, Valentine Nuss ${ }^{1}$, Jérémie Vovelle ${ }^{1}$, \\ Philippe d'Athis ${ }^{2}$, Pierre Jouanny ${ }^{1}$, Alain Putot ${ }^{1, *(\mathbb{D})}$ and Patrick Manckoundia 1,3 \\ 1 Department of Geriatrics and Internal Medicine, Hospital of Champmaillot, University Hospital, \\ 21000 Dijon, France; caroline.laborde@chu-dijon.fr (C.L.); jeremy.barben@chu-dijon.fr (J.B.); \\ anca.mi17@yahoo.com (A.-M.M.); valentine.nuss@chu-dijon.fr (V.N.); jeremie.vovelle@chu-dijon.fr (J.V.); \\ pierre.jouanny@chu-dijon.fr (P.J.); patrick.manckoundia@chu-dijon.fr (P.M.) \\ 2 Department of Biostatistics and Medical Information, François Mitterrand Hospital, University Hospital, \\ 21000 Dijon, France; philippe.athis@chu-dijon.fr \\ 3 UMR Inserm/U1093 Cognition, Action, Sensorimotor Plasticity, University of Burgundy and Franche Comté, \\ 21000 Dijon, France \\ * Correspondence: alain.putot@chu-dijon.fr
}

Received: 18 May 2020; Accepted: 22 June 2020; Published: 24 June 2020

\begin{abstract}
Platelet aggregation inhibitors (PAI) have widely proven their efficiency for the prevention of ischemic cardiovascular events. We aimed to describe PAI prescription in an elderly multimorbid population and to determine the factors that influence their prescription, including the impact of age, comorbidities and frailty, evaluated through a comprehensive geriatric assessment. This cross-sectional study included all patients admitted to the acute geriatric department of a university hospital from November 2016 to January 2017. We included 304 consecutive hospitalized patients aged $88.7 \pm 5.5$ years. One third of the population was treated with PAI. A total of $133(43.8 \%)$ patients had a history of cardiovascular disease, 77 of whom were on PAI. For 16 patients, no indication was identified. The prescription or the absence of PAI were consistent with medical history in $61.8 \%$ of patients. In the multivariate analysis, among the 187 patients with an indication for PAI, neither age (odds ratio $(\mathrm{OR})=1.00 ; 95 \%$ confidence interval $(\mathrm{CI})$ : [0.91-1.08], per year of age), nor comorbidities (OR $=0.97$; $95 \%$ CI: [0.75-1.26], per point of Charlson comorbidity index), nor cognitive disorders (OR $=0.98$; 95\% CI [0.91-1.06] per point of Mini Mental State Examination), nor malnutrition (OR $=1.07 ; 95 \% \mathrm{CI}$ [0.96-1.18], per $\mathrm{g} / \mathrm{L}$ of albumin) were significantly associated with the therapeutic decision. PAI were less prescribed in primary prevention situations, in patients taking anticoagulants and in patients with a history of bleeding. In conclusion, a third of our older comorbid population of inpatients was taking PAI. PAI prescription was consistent with medical history for $61.8 \%$ of patients. Age, multimorbidity and frailty do not appear to have a significant influence on therapeutic decision-making. Further research is needed to confirm such a persistence of cardiovascular preventive strategies in frail older patients from other settings and to assess whether these strategies are associated with a clinical benefit in this specific population.
\end{abstract}

Keywords: age; multimorbidity; frailty; overuse; underuse; antiplatelet agents; platelet aggregation inhibitors; elderly; comprehensive geriatric assessment

\section{Introduction}

Cardiovascular diseases account for $45 \%$ of deaths in Europe, which amounts to more than 4 million deaths per year, $65 \%$ of which occur after the age of 65 [1]. Age is the most significant 
non-modifiable cardiovascular risk factor, and it is also a risk factor for recurrence [2]. In addition, cardiovascular events in the elderly result in a higher rate of long-term disability and dependence [3].

Platelet aggregation inhibitors (PAI) have been shown to be effective for the secondary prevention of cardiovascular disease, and this effect is maintained in older adults [4]. The benefit-risk ratio is less clearly established in primary prevention. In 2018, the ASPirin in Reducing Events in the Elderly (ASPREE) study demonstrated that the use of a PAI for primary prevention does not reduce the risk of cardiovascular events in the elderly, but it does increase the risk of major bleeding [5]. A meta-analysis published in 2019 found that the use of PAI in primary prevention was associated with a lower risk of cardiovascular events but a higher risk of major bleeding [6].

Prescribing drugs is particularly complex in the elderly, and vigilance is required with regard to both excess (overuse) and insufficient treatment (underuse) [7]. PAI is one of the most commonly underused drugs for secondary prevention in geriatrics [8], despite strong evidence that its use is beneficial [9]. However, there is to date little evidence of benefit of preventive strategies in frail older subjects with multiple comorbidities and polypharmacy. Several studies have shown a lower compliance with the recommendations for PAI when physicians treat older patients or patients with dependence or cognitive disorders [10-12]. Evidence shows an inverse relationship between cardiovascular preventive drugs prescription and age [13]. However, there is growing awareness of the importance of multimorbidity, and poor functional and cognitive status, rather than age itself, as factors associated with prognosis and underprescription in the elderly [14-18].

In light of these findings, we conducted a study to analyze the prescription of PAI among patients hospitalized in acute geriatrics. We assessed whether age, multimorbidity and frailty, evaluated by a comprehensive geriatric assessment (CGA), were independently associated with fewer PAI prescriptions.

\section{Methods}

\subsection{Design}

This monocentric observational cross-sectional study was conducted in the acute geriatric department of a university hospital over a 2-month period. The study was conducted in accordance with the Declaration of Helsinki and national standards, and with the approval of the ethics committee of our institution. Data were collected from the medical record, including the systematic CGA performed by the medical team.

\subsection{Population}

We included all consecutive patients admitted to the acute geriatric department from home, the emergency department or another acute care unit at the university hospital between 2 November 2016 and 6 January 2017. Hospitalization in the acute geriatric department during the study period was the unique inclusion criterion. We excluded readmissions over the study period and patients for whom data collected were unavailable in the medical record. There were no other exclusion criteria in the present study.

\subsection{Data Collected}

For each subject, we collected: age, sex, place of residence and the main medical history, including cardiovascular risk factors such as high blood pressure (hypertension), dyslipidemia, chronic kidney disease, diabetes and active smoking. We also collected chronic treatment at admission, including PAI and anticoagulants, history of severe bleeding (intracranial or digestive hemorrhage, hematuria or deep bleeding), transfusion of red blood cells within the previous 6 months, known iron deficiency, and hemoglobin level on admission. Polypharmacy was defined as the routine use of more than five medications [19]. In addition, multimorbidity, cardiovascular risk and CGA were performed for each patient. Consistency of PAI prescription with current guidelines was also established, according to the 
current French guidelines [20], in primary or secondary prevention, in case of high cardiovascular risk or symptomatic atherosclerosis (as defined in Section 2.3.3), respectively.

\subsubsection{Multimorbidity Assessment}

Comorbidities were evaluated by the (non-age-adjusted) Charlson comorbidity index [21]. Multimorbidity was defined by the presence of two chronic diseases or more at admission [22].

\subsubsection{Comprehensive Geriatric Assessment}

Items of the CGA were also collected [23]. The Mini-Mental State Examination (MMSE) score was used to divide subjects into 3 groups according to their score $(\geq 21$, between 10 and 20 or $<10)$. A history of at least two falls in the previous year was documented. Gait speed, Tinetti test or minimum motor test were used to evaluate mobility. Motor fragility was defined as either a gait speed $\leq 0.70 \mathrm{~m} / \mathrm{s}$, a Tinetti test score $\leq 23 / 28$ or a minimum motor test score $<15 / 20$ [24]. Nutrition status was evaluated with the serum albumin level and according to the recommendations for the identification of adult malnutrition [25].

\subsubsection{Cardiovascular Risk Assessment}

A patient was considered to be at high cardiovascular risk if he has complicated diabetes, a glomerular filtration rate $<45 \mathrm{~mL} / \mathrm{min}$ or at least 3 of the following cardiovascular risk factors: age $>50$ years in males and $>60$ years in females, hypertension, diabetes, active smoking and high-density lipoprotein (HDL) cholesterol $\leq 0.40 \mathrm{~g} / \mathrm{L}$ [21]. Cardiovascular events defining symptomatic atherosclerosis were determined according to the French National Health Authority guidelines regarding the prescription of PAI in 2012 [20]: ischemic heart disease, non-cardioembolic stroke or transient ischemic attack, peripheral artery disease (PAD), other ischemic events or an endovascular procedure.

\subsection{Statistical Analyses}

Patients with and without a prescription for PAI were compared in univariate and multivariate analyses. The dichotomous variables were expressed in absolute numbers and percentages, while the quantitative variables were expressed as means and standard deviations in case of normal distribution or as medians and interquartile ranges otherwise. In the univariate analysis, the chi-square test was used to compare qualitative values. Quantitative values were analyzed using the Student's $t$-test. Multivariate analysis with logistic regression was also performed in cases of $p<0.1$ in the bivariate analysis or clinical significance. Significance was set at $p<0.05$. SPSS version 23 (IBM Inc., Armonk, NY, USA) was used for all statistical analyses.

\section{Results}

\subsection{Population}

Three-hundred-and-thirty-three patients were admitted over the target period; 13 (3.9\%) were excluded because their prescription data were missing and $16(4.8 \%)$ because they were readmitted over the study period. Ultimately, 304 patients with a mean age of $88.7 \pm 5.5$ years (extremes 69 and 108 years) were included, of whom $174(57.2 \%)$ were women. A total of 53 patients $(17.4 \%)$ were nursing home residents. A majority of patients were considered multimorbid (non-age-adjusted Charlson score $\geq 2$ for 188 patients $(61.8 \%))$. The following parameters of the CGA were highlighted:

- Cognitive evaluation: 267 patients were divided into three subgroups according to MMSE score: 100 patients (37.5\%) had a score of $\geq 21 / 30,122(45.7 \%)$ a score between 10 and $20 / 30$ and $45(16.9 \%)$ a score $<10 / 20$; 
- Motor skills: In the previous year, 105 patients (34.5\%) had experienced at least two falls. Of the 250 patients for whom the motor evaluation was performed, $211(69.4 \%)$ had motor frailty. The mean gait speed was $0.37 \pm 0.3 \mathrm{~m} / \mathrm{s}$. The mean minimum motor test score was 13.6 $\pm 3.9 / 20$ and the mean Tinetti test score was $20 \pm 5.1 / 28$;

- Nutritional evaluation: The mean serum albumin was $29.2 \pm 4.8 \mathrm{~g} / \mathrm{L}$, and 143 patients $(48.8 \%)$ were found to have severe protein-energy malnutrition.

\subsection{PAI Indications}

Age was a cardiovascular risk factor for all patients. In addition, $217(71.4 \%)$ had hypertension, $81(26.6 \%)$ had dyslipidemia, $85(28.0 \%)$ had diabetes and $5(1.6 \%)$ were active smokers. Fifty-four patients $(17.8 \%)$ had never had a cardiovascular event but had a high cardiovascular risk and could therefore have been treated with PAI for primary prevention.

One-hundred-and-thirty-three patients $(43.8 \%)$ had a history of symptomatic atherosclerosis warranting PAI for secondary prevention. The indication was ischemic heart disease in 69 cases, non-cardioembolic stroke in 67 cases and symptomatic PAD in 18 cases. The other 21 indications were an endovascular procedure for 14 patients and another ischemic event in 7 cases (ischemic colitis, mesenteric ischemia or ischemic optic neuropathy). A total of 31 patients had already experienced several cardiovascular events.

Concerning PAI contraindications and risks, history of severe bleeding was recorded in 40 patients $(13.2 \%)$. It was a digestive hemorrhage in 19 cases, an intracranial hemorrhage in 12 cases and another type (hematuria or deep bleeding) in 9 cases. These events had occurred in the previous year in 19 patients. One-hundred-and-thirty-one patients (43.1\%) were anemic, 30 (9.9\%) patients had hemoglobin levels $\leq 10 \mathrm{~g} / \mathrm{L}, 9(3 \%)$ had hemoglobin levels $\leq 8 \mathrm{~g} / \mathrm{dL}$ and 17 had received a red blood cell transfusion in the six months prior to hospitalization.

\subsection{PAI Prescription}

On admission, 103 patients (33.9\%) were taking PAI: 83 on aspirin alone (80.6\%), 16 on clopidogrel alone $(15.5 \%)$ and $4(3.9 \%)$ on combined therapy (aspirin and clopidogrel in 3 cases and aspirin and ticagrelor in 1 case). Of these 103 patients, 77 were on PAI for secondary prevention, 10 for primary prevention and 16 had no indication (overuse). The 77 cases of symptomatic atherosclerosis (one or more associated cases) included 41 cases of coronary heart disease, 36 strokes, 15 PAD and 7 other indications.

The prescription or non-prescription of PAI was consistent with the patient's medical history in $61.8 \%$ of the population (i.e., 188 patients: PAI for primary prevention for 10 patients, for secondary prevention for 77 patients, no indication of PAI for 101 patients). Figure 1 summarizes the treatments according to the patients' level of cardiovascular risk.

In the univariate analysis of the 187 patients with an indication for PAI (Table 1), age, gender and nursing home resident status were not significantly associated with PAI prescription. The Charlson scores and rates of motor disorders were similar in the two groups. Patients classified as primary prevention or taking anticoagulants were less frequently on PAI, whereas patients with coronary artery disease were more frequently prescribed PAI. Proton pump inhibitors and statins co-prescriptions were significantly more frequent among patients on PAI.

In the multivariate analysis, age, multimorbidity and altered motor, cognitive or nutritional status did not significantly influence the prescription of PAI (Table 2). Polypharmacy was significantly more frequent in patients prescribed PAI (OR $=4.14 ; 95 \%$ CI $[1.12-15.29] ; p=0.033)$. Patients with an indication for PAI as primary prevention were less likely to be treated $(\mathrm{OR}=0.04 ; 95 \% \mathrm{CI}[0.01-0.20]$; $p<0.001)$. On the contrary, symptomatic PAD was more frequent in patients on PAI (OR $=5.30 ; 95 \%$ CI [1.07-26.2]; $p=0.041)$. Compliance with the recommendations regarding PAI was lower in patients with a history of bleeding and/or anticoagulant therapy ( $\mathrm{OR}=0.14 ; 95 \% \mathrm{CI}[0.03-0.63] ; p=0.030$ and $\mathrm{OR}=0.01 ; 95 \% \mathrm{CI}[0.004-0.05] ; p<0.001$, respectively). 


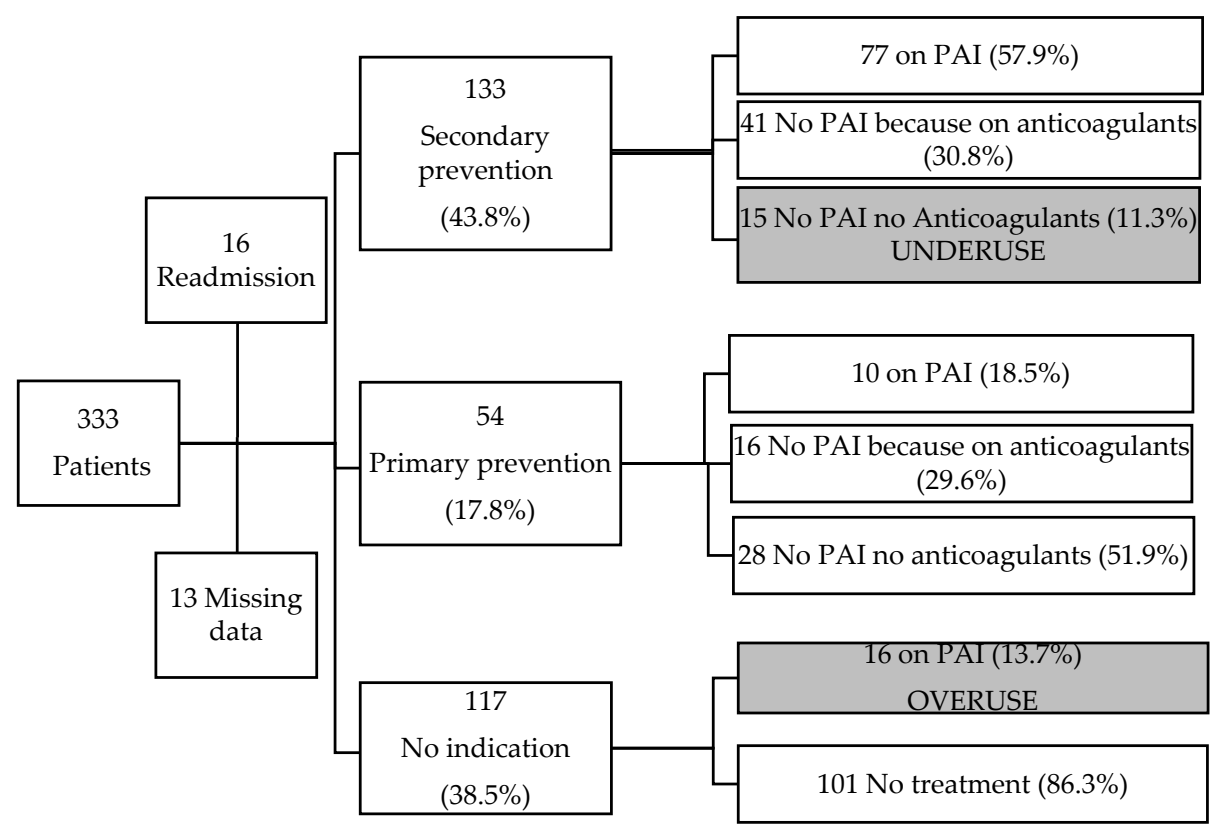

Figure 1. Flow chart. PAI: platelet aggregation inhibitors. The black text boxes indicate inconsistency with current guidelines [20].

Table 1. Characteristics of patients with an indication for platelet aggregation inhibitors (PAI) (n (\%) or mean \pm standard deviation).

\begin{tabular}{|c|c|c|c|c|}
\hline & & No PAI $(n=100)$ & PAI $(n=87)$ & $p$ \\
\hline \multicolumn{5}{|c|}{ Socio-Demographic Characteristics } \\
\hline Gender & Female & $58(58)$ & $45(51.7)$ & 0.438 \\
\hline \multirow[t]{4}{*}{ Age (years) } & Mean \pm SD & $87.4 \pm 5.4$ & $87.3 \pm 4.9$ & 0.881 \\
\hline & $\leq 80$ & $8(8)$ & $5(5.7)$ & 0.774 \\
\hline & $81-89$ & $55(55)$ & $55(63.2)$ & 0.282 \\
\hline & $\geq 90$ & $37(37)$ & $27(31.0)$ & 0.422 \\
\hline Nursing home & & $23(23)$ & $16(18.4)$ & 0.463 \\
\hline \multicolumn{5}{|l|}{ Comorbidities } \\
\hline & Chronic heart failure & $36(36)$ & $31(35.6)$ & 0.958 \\
\hline & Cognitive disorders & $50(50)$ & $40(46)$ & 0.583 \\
\hline & Chronic kidney disease & $5(5)$ & $7(8)$ & 0.261 \\
\hline & Chronic respiratory disease & $18(18)$ & $14(16.1)$ & 0.730 \\
\hline & Diabetes & $31(31)$ & $26(29.9)$ & 0.869 \\
\hline & Neoplasia & $10(10)$ & $10(11.5)$ & 0.742 \\
\hline & Peptic ulcer & $9(9)$ & $4(4.6)$ & 0.238 \\
\hline Multimorbidity & Charlson Index $\geq 2$ & $78(78)$ & $68(78.2)$ & 0.988 \\
\hline \multicolumn{5}{|c|}{ Comprehensive Geriatric Assessment } \\
\hline \multirow{4}{*}{ MMSE score } & Mean \pm SD & $17.6 \pm 6.1$ & $17.9 \pm 7.9$ & 0.782 \\
\hline & $\geq 21$ & $28(28)$ & $32(36.8)$ & 0.355 \\
\hline & $10-20$ & $49(49)$ & $27(31)$ & 0.027 \\
\hline & $<10$ & $11(11)$ & $17(19.5)$ & 0.227 \\
\hline \multirow[t]{2}{*}{ Motor skills } & Motor disorders & $67(87)$ & $69(79.3)$ & 0.210 \\
\hline & Falls & $38(38)$ & $27(31)$ & 0.346 \\
\hline \multirow[t]{2}{*}{ Nutrition } & Serum albumin, (g/L) & $28.2 \pm 5.5$ & $29.3 \pm 4.1$ & 0.136 \\
\hline & Severe malnutrition * & $54(54)$ & $36(41.4)$ & 0.156 \\
\hline
\end{tabular}


Table 1. Cont

\begin{tabular}{|c|c|c|c|}
\hline & No PAI $(n=100)$ & PAI $(n=87)$ & $p$ \\
\hline \multicolumn{4}{|l|}{ Co-Prescriptions } \\
\hline Proton pump inhibitors & $37(37)$ & $45(51.2)$ & 0.043 \\
\hline Statins & $23(23)$ & $43(49.4)$ & $<0.001$ \\
\hline SSRI & $15(15)$ & $16(18.4)$ & 0.534 \\
\hline Polypharmacy (>5 treatments) & $81(81)$ & $78(89.7)$ & 0.105 \\
\hline \multicolumn{4}{|l|}{ Cardiovascular History } \\
\hline Primary Prevention & $44(44)$ & $10(11.5)$ & 0.001 \\
\hline Coronary artery disease & $28(28)$ & $41(47.1)$ & 0.006 \\
\hline Secondary & $31(31)$ & $36(41.4)$ & 0.124 \\
\hline Symptomatic PAD & $8(8)$ & $15(17.2)$ & 0.051 \\
\hline Other indications ** & $13(13)$ & $7(8)$ & 0.133 \\
\hline \multicolumn{4}{|l|}{ Bleeding Risk } \\
\hline Anticoagulants & $57(57)$ & $7(8.0)$ & $<0.001$ \\
\hline History of bleeding & $12(12)$ & $8(9.2)$ & 0.554 \\
\hline Anemia & $47(47)$ & $42(48.3)$ & 0.803 \\
\hline RBC transfusion within 6 months & $5(5)$ & $6(6.9)$ & 0.757 \\
\hline
\end{tabular}

MMSE: Mini Mental State Examination; PAD: peripheral artery disease; RBC: reb blood cells; SSRI: selective serotonin reuptake inhibitors. * Severe denutrition: according to the Academy Malnutrition Work Group criteria [25]. ** Other indications: other ischemic accident, endovascular procedure, percutaneous aortic valve implantation.

Table 2. Multivariate analysis of factors associated with prescription of platelet aggregation inhibitors.

\begin{tabular}{lccc}
\hline & Odds Ratio & $\mathbf{9 5} \% \mathbf{C I}$ & $p$ \\
\hline Age, Comorbidities and Frailty & & & \\
\hline Age (per year) & 1.00 & $0.91-1.08$ & 0.835 \\
Charlson index (per point) & 0.97 & $0.75-1.26$ & 0.803 \\
MMSE (per point) & 0.98 & $0.91-1.06$ & 0.673 \\
Motor disorders & 2.01 & $0.32-13.75$ & 0.438 \\
Falls & 1.56 & $0.60-4.04$ & 0.364 \\
Albumin (g per L) & 1.07 & $0.96-1.18$ & 0.249 \\
Polypharmacy ( $\geq 5$ treatments) & 4.14 & $1.12-15.29$ & 0.033 \\
\hline Cardiovascular History & & & \\
\hline Primary prevention & 0.04 & $0.01-0.20$ & $<0.001$ \\
Coronary artery disease & 1.10 & $0.28-4.32$ & 0.897 \\
Stroke & 0.76 & $0.19-3.02$ & 0.693 \\
Symptomatic PAD & 5.30 & $1.07-26.2$ & 0.041 \\
Other indication * & 0.90 & $0.02-0.55$ & 0.009 \\
\hline Bleeding Risk & & & \\
\hline History of bleeding & 0.14 & $0.03-0.63$ & 0.030 \\
Anticoagulants & 0.01 & $0.004-0.05$ & $<0.001$ \\
\hline
\end{tabular}

CI: confidence interval, MMSE: Mini Mental State Examination; PAD: peripheral artery disease. ${ }^{*}$ Other indication: other ischemic accident, endovascular procedure, percutaneous aortic valve implantation.

\section{Discussion}

The interest of this study lies in its exhaustive nature as well at the target population-an elderly multimorbid population taking multiple medications.

This work highlights the high prevalence of cardiovascular disease in the elderly considering that nearly a half of the population had an indication for PAI. Such epidemiological data are rare because most studies focus on specific indications for PAI and few consider the hospitalized elderly 
population as a whole. Here we provide a comprehensive record of the geriatric context associated with prescription or non-prescription of PAI.

\subsection{PAI in Older Patients: From Underuse to Overuse}

Treatments for cardiovascular disease are the most widely consumed drug class in the elderly population. This study shows that more than one third of a hospitalized geriatric population was on PAI, which is consistent with retrospective data obtained in an elderly French ambulatory population [26]. PAI prescription was consistent with medical history in $61.8 \%$ of patients. Despite strong supporting evidence, levels of compliance to the recommendations are often disappointing [27]. This is especially true in the geriatric population, where there is a paradoxical underuse of PAI in patients with a high risk of cardiovascular events $[11,28,29]$. In our work, the prescription of PAI was observed in only $58 \%$ of patients with an indication for PAI as secondary prevention (underuse). Long-term PAI have proven their effectiveness in symptomatic atherosclerosis, reducing cardiovascular mortality and severe cardiovascular morbidity by $25 \%$ [9]. This benefit is recognized as greater than the risk of bleeding [30]. Underuse of PAI for documented atherosclerosis is one of the most common instances of underuse in geriatrics [8]. One study showed that $40 \%$ of patients received neither PAI nor anticoagulants after stroke and a hospital stay in geriatrics [10]. Another investigation in patients discharging from hospital after myocardial infarction reported a PAI prescription in $88 \%$ of patients aged $<75$ years but only in $66 \%$ after the age of 84 [11]. Another study found that only a half of patients with a history of stroke or coronary artery disease had received a prescription for PAI prior to hospitalization [31].

Ten patients with a high cardiovascular risk were prescribed PAI for primary prevention, as recommended in the French guidelines from 2012 [20]. However, the Australian ASPREE randomized controlled trial, which compared the prescription of low-dose aspirin to a placebo in primary prevention, showed no benefit for cardiovascular mortality, disability or all cause of mortality in the PAI group [5]. Based on these data, the European Society of Cardiology (ESC) chose in 2016 to no longer recommend the use of PAI for primary prevention [32].

In our population, 16 of the 117 patients without identified cardiovascular risk factors were taking PAI without any indication (overuse). This is a frequent occurrence in geriatrics. A French study from 2011 found that, among 219 patients aged 70 years and older, $16.9 \%$ of PAI prescriptions were off-label [33]. Considering that $5 \%$ of patients have experienced an episode of bleeding, the authors concluded that it was unacceptable to put patients at such a risk.

\subsection{Factors Associated with PAI Prescriptions}

In our study, we did not find that patient characteristics, regardless of the medical history, led to changes in therapy. Notably, though patient age has previously been described as a risk factor for the underuse of PAI, it did not influence prescriptions in our population [27,31]. Underuse of beneficial medications is frequently reported for the oldest old, including for PAI [34]. In contrast, Filippi et al. found that prescriptions after stroke were more appropriate in patients aged $>65$ years and in men [35]. Concerning the indications of PAI in secondary prevention, symptomatic PAD was associated with a higher rate of PAI prescription than other indications, including history of stroke and coronary artery disease. To our knowledge, there are no data in the literature to compare with these results. We may assume that pain related to symptomatic PAD could reinforce guidelines adherence, compared with asymptomatic pathologies.

Multimorbidity, evaluated by the Charlson index [21], was not associated with PAI underuse in our series. Our findings are contrary to a previous study that found a low Charlson index to be an independent predictive factor for the use of PAI in the acute phase of myocardial infarction [36]. More generally, multimorbidity has been associated with underuse of indicated medications in hospitalized American veterans [37]. However, the existence of systematic associations in drug prescription leading to the establishment of patterns of polypharmacy could dampen the underuse of PAI in multimorbid patients [38]. Interestingly, we found PAI prescription to be independently 
associated with polypharmacy. The frequent co-prescription of statins with PAI, highlighted in our series, has been already identified as belonging to a pattern of polypharmacy [38]. This association is clinically relevant as these two therapeutic classes have the same main indications (i.e., primary or secondary atherosclerosis prevention). Prevention of PAI-induced hemorrhagic risk by proton pump inhibitors in older patients, although not systematically recommended, is also common in practice [39] and increases the risk of polypharmacy in patients on PAI.

The CGA did not individualize any factor associated with PAI prescription. To our knowledge, such findings have never been published for PAI, but similar results were found for anticoagulants in a geriatric setting [40]. We found no link between motor disability or falls and the prescription of PAI. However, one study showed that patients taking PAI were at an increased risk of bleeding in the event of a fall [35]. In our work, cognitive disorders were not a barrier to the prescription of PAI, while an Italian study showed that patients with memory problems were less likely to be treated with PAI after hospitalization for stroke [10]. It appears that physician knowledge and experience, as well as their own perception of ageing, could influence therapeutic decision-making in older multimorbid patients [41-43]

In our study, there was a strong disinclination to prescribe both PAI and anticoagulants: in $30 \%$ of cases, the absence of PAI treatment when indicated was justified by the concomitant prescription of anticoagulants. In 2014, the ESC approved the discontinuation of PAI in patients with stable coronary artery disease treated with long-term anticoagulant therapy [10]. This attitude is in line with the data in the literature demonstrating that the risk of bleeding is doubled with a PAI-anticoagulant combination compared with monotherapy [44], without any decrease in cardiovascular event incidence [45]. This would also explain why PAI were less prescribed in patients with a history of bleeding in this study.

\subsection{Limitations}

There are some limitations to this study. First it was carried out in a university hospital geriatrics department which is accustomed to managing very frail patients. The monocentric design limits the generalizability of this study seeing that these patients may be managed quite differently in other health care settings and in ambulatory care. Second, the CGA was performed in acute geriatrics during hospitalization for an acute event and may therefore not reflect the patient's aptitudes before hospitalization. Third, the relatively small sample size is responsible for a potential lack of power and weak associations between PAI prescription and the variables of interest cannot be excluded. Last, frailty was not evaluated by a validated instrument. However, our series has enabled us to provide a comprehensive evaluation of geriatric factors potentially associated with PAI prescription.

\section{Conclusions}

A third of our hospitalized older population had a prescription for PAI on admission. Even though it has proven effective for the prevention of cardiovascular disease, the prescription of PAI was consistent with the patient's medical history in only $60 \%$ of cases. Among patients with an indication for PAI, anticoagulant use and bleeding history were associated with less frequent prescription of PAI. However, age, multimorbidity, motor disabilities, cognitive disorders and malnutrition did not significantly influence prescribing in this geriatric setting. Further studies are needed to confirm these findings.

Author Contributions: Conceptualization, C.L., A.P., and P.M.; methodology, A.P., and P.d.; software, J.B.; validation, C.L., A.P. and P.M.; formal analysis, A.P., P.d.; investigation, C.L., A.-M.M.,V.N., J.V.; resources, J.B.; data curation, A.P.; writing—original draft preparation, C.L.; writing—review and editing, J.B., A.-M.M., V.N., J.V., P.J., A.P., P.M.; visualization, P.M., and P.J.; supervision, A.P., and P.M.; project administration, P.M. All authors have read and agreed to the published version of the manuscript.

Funding: This research received no external funding. 
Acknowledgments: The authors are grateful to Suzanne Rankin, a native English speaker, who read and corrected this article.

Conflicts of Interest: The authors declare no conflict of interest.

\section{References}

1. Townsend, N.; Wilson, L.; Bhatnagar, P.; Wickramasinghe, K.; Rayner, M.; Nichols, M. Cardiovascular disease in Europe: Epidemiological update 2016. Eur. Heart J. 2016, 37, 3232-3245. [CrossRef] [PubMed]

2. Rothwell, P.M.; Coull, A.J.; Silver, L.E.; Fairhead, J.F.; Giles, M.F.; Lovelock, C.E.; Redgrave, J.N.E.; Bull, L.M.; Welch, S.J.V.; Cuthbertson, F.C.; et al. Population-based study of event-rate, incidence, case fatality, and mortality for all acute vascular events in all arterial territories (Oxford Vascular Study). Lancet 2005, 366, 1773-1783. [CrossRef]

3. Béjot, Y.; Rouaud, O.; Jacquin, A.; Osseby, G.-V.; Durier, J.; Manckoundia, P.; Pfitzenmeyer, P.; Moreau, T.; Giroud, M. Stroke in the very old: Incidence, risk factors, clinical features, outcomes and access to resources-A 22-year population-based study. Cerebrovasc. Dis. Basel Switz. 2010, 29, 111-121. [CrossRef] [PubMed]

4. Dornbrook-Lavender, K.A.; Roth, M.T.; Pieper, J.A. Secondary prevention of coronary heart disease in the elderly. Ann. Pharmacother. 2003, 37, 1867-1876. [CrossRef] [PubMed]

5. McNeil, J.J.; Wolfe, R.; Woods, R.L.; Tonkin, A.M.; Donnan, G.A.; Nelson, M.R.; Reid, C.M.; Lockery, J.E.; Kirpach, B.; Storey, E.; et al. Effect of Aspirin on Cardiovascular Events and Bleeding in the Healthy Elderly. N. Engl. J. Med. 2018, 379, 1509-1518. [CrossRef]

6. Zheng, S.L.; Roddick, A.J. Association of Aspirin Use for Primary Prevention with Cardiovascular Events and Bleeding Events: A Systematic Review and Meta-analysis. JAMA 2019, 321, 277-287. [CrossRef]

7. Haute Autorité de Santé-Prescription Médicamenteuse chez le Sujet Agé (PMSA)-Programme Pilote 2006-2013. Available online: https://www.has-sante.fr/portail/jcms/c_675707/fr/prescription-medicamenteuse-chez-lesujet-age-pmsa-programme-pilote-2006-2013 (accessed on 21 February 2019).

8. Andro, M.; Coutard, A.; Gentric, A. Underuse in elderly adults: An underestimated suboptimal prescribing. J. Am. Geriatr. Soc. 2012, 60, 1582-1583. [CrossRef]

9. Antithrombotic Trialists' Collaboration. Collaborative meta-analysis of randomised trials of antiplatelet therapy for prevention of death, myocardial infarction, and stroke in high risk patients. BMJ 2002, 324, 71-86. [CrossRef]

10. Volpato, S.; Maraldi, C.; Blè, A.; Ranzini, M.; Rita Atti, A.; Dominguez, L.J.; Barbagallo, M.; Fellin, R.; Zuliani, G.; Gruppo Italiano di Farmacoepidemiologia nell'Anziano (GIFA). Prescription of antithrombotic therapy in older patients hospitalized for transient ischemic attack and ischemic stroke: The GIFA study. Stroke 2004, 35, 913-917. [CrossRef]

11. Di Bari, M.; Degli Esposti, L.; Veronesi, C.; Pecorelli, S.; Fini, M.; Baldasseroni, S.; Mossello, E.; Fumagalli, S.; Scatigna, M.; Marchionni, N. Combination evidence-based therapy is effective in the oldest "old patients" following myocardial infarction. The 'Salute e Benessere nell'Anziano' (SeBA) observational study. Intern. Emerg. Med. 2016, 11, 677-685. [CrossRef]

12. Lichtman, J.H.; Naert, L.; Allen, N.B.; Watanabe, E.; Jones, S.B.; Barry, L.C.; Bravata, D.M.; Goldstein, L.B. Use of antithrombotic medications among elderly ischemic stroke patients. Circ. Cardiovasc. Qual. Outcomes 2011, 4, 30-38. [CrossRef] [PubMed]

13. Maraldi, C.; Lattanzio, F.; Onder, G.; Gallerani, M.; Bustacchini, S.; De Tommaso, G.; Volpato, S. Variability in the prescription of cardiovascular medications in older patients: Correlates and potential explanations. Drugs Aging 2009, 26 (Suppl. 1), 41-51. [CrossRef] [PubMed]

14. Landi, F.; Cesari, M.; Onder, G.; Zamboni, V.; Lattanzio, F.; Russo, A.; Barillaro, C.; Bernabei, R.; SILVERNET-HC Study Group. Antithrombotic drugs in secondary stroke prevention among a community dwelling older population. J. Neurol. Neurosurg. Psychiatry 2003, 74, 1100-1104. [CrossRef]

15. Schmader, K.E.; Hanlon, J.T.; Fillenbaum, G.G.; Huber, M.; Pieper, C.; Horner, R. Medication use patterns among demented, cognitively impaired and cognitively intact community-dwelling elderly people. Age Ageing 1998, 27, 493-501. [CrossRef] [PubMed] 
16. Liu, E.; Dyer, S.M.; O’Donnell, L.K.; Milte, R.; Bradley, C.; Harrison, S.L.; Gnanamanickam, E.; Whitehead, C.; Crotty, M. Association of cardiovascular system medications with cognitive function and dementia in older adults living in nursing homes in Australia. J. Geriatr. Cardiol. JGC 2017, 14, 407-415. [CrossRef] [PubMed]

17. Jokanovic, N.; Kautiainen, H.; Bell, J.S.; Tan, E.C.K.; Pitkälä, K.H. Change in Prescribing for Secondary Prevention of Stroke and Coronary Heart Disease in Finnish Nursing Homes and Assisted Living Facilities. Drugs Aging 2019, 36, 571-579. [CrossRef]

18. Pedersen, R.A.; Petursson, H.; Hetlevik, I. Stroke follow-up in primary care: A Norwegian modelling study on the implications of multimorbidity for guideline adherence. BMC Fam. Pract. 2019, 20, 138. [CrossRef]

19. Bushardt, R.L.; Massey, E.B.; Simpson, T.W.; Ariail, J.C.; Simpson, K.N. Polypharmacy: Misleading, but manageable. Clin. Interv. Aging 2008, 3, 383-389. [CrossRef]

20. HAS Recommandations Agents Antiplaquettaires. Available online: http://www.has-sante.fr/portail/upload/ docs/application/pdf/2012-07/12irp06_reco_agents_antiplaquettaires.pdf (accessed on 1 April 2017).

21. Charlson, M.E.; Pompei, P.; Ales, K.L.; MacKenzie, C.R. A new method of classifying prognostic comorbidity in longitudinal studies: Development and validation. J. Chronic Dis. 1987, 40, 373-383. [CrossRef]

22. Vetrano, D.L.; Palmer, K.; Marengoni, A.; Marzetti, E.; Lattanzio, F.; Roller-Wirnsberger, R.; Lopez Samaniego, L.; Rodríguez-Mañas, L.; Bernabei, R.; Onder, G.; et al. Frailty and Multimorbidity: A Systematic Review and Meta-analysis. J. Gerontol. A Biol. Sci. Med. Sci. 2019, 74, 659-666. [CrossRef]

23. Parker, S.G.; McCue, P.; Phelps, K.; McCleod, A.; Arora, S.; Nockels, K.; Kennedy, S.; Roberts, H.; Conroy, S. What is Comprehensive Geriatric Assessment (CGA)? An umbrella review. Age Ageing 2018, 47, 149-155. [CrossRef] [PubMed]

24. Mourey, F.; Camus, A.; d'Athis, P.; Blanchon, M.-A.; Martin-Hunyadi, C.; de Rekeneire, N.; Pfitzenmeyer, P. Mini motor test: A clinical test for rehabilitation of patients showing psychomotor disadaptation syndrome (PDS). Arch. Gerontol. Geriatr. 2005, 40, 201-211. [CrossRef] [PubMed]

25. White, J.V.; Guenter, P.; Jensen, G.; Malone, A.; Schofield, M.; Academy Malnutrition Work Group; ASPEN Malnutrition Task Force; ASPEN Board of Directors. Consensus statement: Academy of Nutrition and Dietetics and American Society for Parenteral and Enteral Nutrition: Characteristics recommended for the identification and documentation of adult malnutrition (undernutrition). JPEN J. Parenter. Enter. Nutr. 2012, 36, 275-283. [CrossRef] [PubMed]

26. Manckoundia, P.; Buzens, J.-B.; Mahmoudi, R.; d'Athis, P.; Martin, I.; Laborde, C.; Menu, D.; Putot, A. The prescription of antiplatelet medication in a very elderly population: An observational study in 15,141 ambulatory subjects. Int. J. Clin. Pract. 2017, 71. [CrossRef]

27. Maggioni, A.P.; Rossi, E.; Cinconze, E.; Roggeri, D.P.; Roggeri, A.; Fabbri, G.; De Rosa, M.; ARNO Cardiovascular Observatory. Outcomes, health costs and use of antiplatelet agents in 7,082 patients admitted for an acute coronary syndrome occurring in a large community setting. Cardiovasc. Drugs Ther. 2013, 27, 333-340. [CrossRef]

28. Pereira, M.; Araújo, C.; Dias, P.; Lunet, N.; Subirana, I.; Marrugat, J.; Capewell, S.; Bennett, K.; Azevedo, A. Age and sex inequalities in the prescription of evidence-based pharmacological therapy following an acute coronary syndrome in Portugal: The EURHOBOP study. Eur. J. Prev. Cardiol. 2014, 21, 1401-1408. [CrossRef]

29. Austin, P.C.; Tu, J.V.; Ko, D.T.; Alter, D.A. Factors associated with the use of evidence-based therapies after discharge among elderly patients with myocardial infarction. CMAJ 2008, 179, 901-908. [CrossRef]

30. Lenzi, J.; Rucci, P.; Castaldini, I.; Protonotari, A.; Di Pasquale, G.; Di Martino, M.; Perrone, E.; Forti, P.; Fantini, M.P. Does age modify the relationship between adherence to secondary prevention medications and mortality after acute myocardial infarction? A nested case-control study. Eur. J. Clin. Pharmacol. 2015, 71, 243-250. [CrossRef]

31. Wawruch, M.; Slezakova, V.; Murin, J.; Kuzelova, M.; Dukat, A.; Zabka, M.; Leitmann, T.; Tisonova, J.; Kallay, Z. The use of antiplatelet medication in hospitalised elderly patients. Bratisl. Lek. Listy 2015, 116, 533-538. [CrossRef]

32. Piepoli, M.F.; Hoes, A.W.; Agewall, S.; Albus, C.; Brotons, C.; Catapano, A.L.; Cooney, M.-T.; Corrà, U.; Cosyns, B.; Deaton, C.; et al. 2016 European Guidelines on cardiovascular disease prevention in clinical practice: The Sixth Joint Task Force of the European Society of Cardiology and Other Societies on Cardiovascular Disease Prevention in Clinical Practice (constituted by representatives of 10 societies and by invited experts) Developed with the special contribution of the European Association for Cardiovascular Prevention \& Rehabilitation (EACPR). Eur. Heart J. 2016, 37, 2315-2381. [CrossRef] 
33. Cadiou, G.; Adam, M.; Caussin, M.; Landrin, I.; Mariette, N.; Capet, C.; Mouton-Schleifer, D.; Remy, E.; Kadri, N.; Doucet, J. Antiplatelet drugs in the elderly: Prescriptions often inappropriate and reduced tolerance by associated diseases and drugs. Fundam. Clin. Pharmacol. 2012, 26, 307-313. [CrossRef] [PubMed]

34. Kuzuya, M.; Masuda, Y.; Hirakawa, Y.; Iwata, M.; Enoki, H.; Hasegawa, J.; Cheng, X.W.; Iguchi, A. Underuse of medications for chronic diseases in the oldest of community-dwelling older frail Japanese. J. Am. Geriatr. Soc. 2006, 54, 598-605. [CrossRef] [PubMed]

35. Filippi, A.; Bignamini, A.A.; Sessa, E.; Samani, F.; Mazzaglia, G. Secondary prevention of stroke in Italy: A cross-sectional survey in family practice. Stroke 2003, 34, 1010-1014. [CrossRef] [PubMed]

36. Aboal, J.; Llaó, I.; García García, C.; Sans-Roselló, J.; Sambola, A.; Andrea, R.; Tomás, C.; Bonet, G.; Ariza-Solé, A.; Viñas, D.; et al. Comorbidity and low use of new antiplatelets in acute coronary syndrome. Aging Clin. Exp. Res. 2019. [CrossRef]

37. Wright, R.M.; Sloane, R.; Pieper, C.F.; Ruby-Scelsi, C.; Twersky, J.; Schmader, K.E.; Hanlon, J.T. Underuse of indicated medications among physically frail older US veterans at the time of hospital discharge: Results of a cross-sectional analysis of data from the Geriatric Evaluation and Management Drug Study. Am. J. Geriatr. Pharmacother. 2009, 7, 271-280. [CrossRef]

38. Calderón-Larrañaga, A.; Gimeno-Feliu, L.A.; González-Rubio, F.; Poblador-Plou, B.; Lairla-San José, M.; Abad-Díez, J.M.; Poncel-Falcó, A.; Prados-Torres, A. Polypharmacy patterns: Unravelling systematic associations between prescribed medications. PLoS ONE 2013, 8, e84967. [CrossRef]

39. Dipanda, M.; Pioro, L.; Buttard, M.; d'Athis, P.; Asgassou, S.; Putot, S.; Deïdda, M.; Laborde, C.; Putot, A.; Manckoundia, P. Évaluation de la prescription des inhibiteurs de la pompe à protons chez la personne âgée de 75 ans et plus dans un service de gériatrie aiguë. Therapies 2017, 72, 669-675. [CrossRef]

40. Dalleur, O.; Wouters, D.; Spinewine, A.; Boland, B.; Maes, F.; Scavee, C.; Henrard, S. Risk scores and geriatric profile: Can they really help us in anticoagulation decision making among older patients suffering from atrial fibrillation? Clin. Interv. Aging 2014, 1091. [CrossRef]

41. Voigt, K.; Gottschall, M.; Köberlein-Neu, J.; Schübel, J.; Quint, N.; Bergmann, A. Why do family doctors prescribe potentially inappropriate medication to elderly patients? BMC Fam. Pract. 2016, 17, 93. [CrossRef]

42. Jansen, J.; McKinn, S.; Bonner, C.; Irwig, L.; Doust, J.; Glasziou, P.; Bell, K.; Naganathan, V.; McCaffery, K. General Practitioners' Decision Making about Primary Prevention of Cardiovascular Disease in Older Adults: A Qualitative Study. PLoS ONE 2017, 12, e0170228. [CrossRef]

43. Schuling, J.; Gebben, H.; Veehof, L.J.G.; Haaijer-Ruskamp, F.M. Deprescribing medication in very elderly patients with multimorbidity: The view of Dutch GPs. A qualitative study. BMC Fam. Pract. 2012, 13, 56. [CrossRef] [PubMed]

44. Shireman, T.I.; Howard, P.A.; Kresowik, T.F.; Ellerbeck, E.F. Combined anticoagulant-antiplatelet use and major bleeding events in elderly atrial fibrillation patients. Stroke 2004, 35, 2362-2367. [CrossRef] [PubMed]

45. Fox, K.A.A.; Velentgas, P.; Camm, A.J.; Bassand, J.-P.; Fitzmaurice, D.A.; Gersh, B.J.; Goldhaber, S.Z.; Goto, S.; Haas, S.; Misselwitz, F.; et al. Outcomes Associated with Oral Anticoagulants Plus Antiplatelets in Patients with Newly Diagnosed Atrial Fibrillation. JAMA Netw. Open 2020, 3, e200107. [CrossRef] [PubMed]

(C) 2020 by the authors. Licensee MDPI, Basel, Switzerland. This article is an open access article distributed under the terms and conditions of the Creative Commons Attribution (CC BY) license (http://creativecommons.org/licenses/by/4.0/). 